\title{
SINUS LIFTING AND VARIETIES OF SUBANTRAL IMPLANTATION IN THE USE OF SCREW INTRABONE IMPLANTS
}

\author{
Tihomir Georgiev \\ Department of Oral and Maxillofacial Surgery \\ Medical University of Varna
}

\section{SUMMARY:}

There has been a long-lasting dispute over the question whether the screw or cylindrical implants are better to use. Subantral augmentation is one of the places which gives superiority to screw implants due to the opportunity to ensure their primary stabilization, hence to subject them to a single moment stress and to reduce surgical interventions. The author tests screw implants in three different clinical conditions of the maxillary sinus. The results of the clinical observations confirm the potentials of screw implants in intricate clinical varieties of "sinus procedans".

Key words: sinus lifting, subantral augmentation, screw intrabone implants

The article is a review of the 3 -year-long experience in the application of screw intrabone implants.

\section{MATERIALS AND METHODS:}

In the conditions of ambulatory surgical practice it was carried out treatment of 45 patients with defects of the maxilla who had indications for subantral implantation and displayed insufficient bone volumes in the section of the maxillary sinus. All patients (26 women and 19 men aged between 25 and 50) were evaluated as "practically healthy" - i.e. without concomitant diseases. This fact was confirmed by the absence of clinical subjective and objective data, characteristic of exhibited concomitant pathology.

During the pre-surgical period it was made clinical - rentgenological and laboratory test. A mandatory component of the rentgenological test was the orthopantomogram. Scan of the maxilla was made if there was need for a fuller visualization in the region of the probable surgery.

During the stage of planning of the method of implantation, there were used the implant classifications of: Misch-Judy (1985), based on the quantitative clinical - rentgenological principles and of Zarb-Lekholm (1985), primarily based on qualitative clinical - rentgenological principles.
In accordance with the classification of Mish-Judy, all patients were divided in the following groups:

$1^{\text {st }}$ group (28) - patients, having bone volume in the region of the sinus with respect to height, width and length, not less than $5 \mathrm{~mm}$ (here we used this particular criterion for minimal bone quantity which is necessary in order to secure primary stabilization of an implant with a minimal diameter of $3.5 \mathrm{~mm}$ in the bone when it is inserted).

$2^{\text {nd }}$ group (15) - patients having bone volume with regard to height less than $5 \mathrm{~mm}$ (the atrophy results in increased sinus cavity)

$3^{\text {rd }}$ group (2) - patients having bone volume with regard to height less than $5 \mathrm{~mm}$ (the atrophy results in the resorbtion of the alveolar crest due to extracted teeth in the recent past).

The patients of the $1^{\text {st }}$ group underwent sinus lifting based on the classical method with direct implantation. There were inserted from 2 to 4 implants, as a rule with a minimal length of $10 \mathrm{~mm}$. The so formed residual sinus volume was filled with bone material (Bio-Oss or NanoBone). Total number of implants -75 .

The patients of the $2^{\text {nd }}$ group underwent sinus lifting with anthroplasty. Bio-Oss was used as bone material. After 6-10 months, after check x-rays were made, there were inserted implants which in such cases are referred to as "deferred". For that purpose, as a rule, there are used implants $11.5 \mathrm{~mm}$ long. Total number of implants inserted - 40.

The patients of the $3^{\text {rd }}$ group underwent sinus lifting in combination with autogenic bone plasty of the alveolar process of the maxilla and direct implantation. Using a similar method we applied a resorbent collagen membrane and osteoplastic bone material - NanoBone. Number of implants inserted in that way -5 .

\section{RESULTS:}

No complications were observed during the dynamic follow-up and clinical - rentgenological tests within 6 months. The intrabone parts of the implants were stable and displayed all features of osteointegration. The insertion of prostheses was implemented after placement of suprastructures. 


\section{DISCUSSION:}

The surgical stage should be preceded by a thorough clinical and rentgenological investigation and surgery planning. The "bone materials" used in the subantral surgery - NanoBone and Bio-Oss proved their efficiency.
The successful 3-year experience in the use of screw implants evidences their high quality and efficiency in sinus lifting in combination with different varieties of subantral implantation.

\section{REFERENCES:} 1. Wheeler, S. L., Holmes, R. E.,
Calhoun, C. J. - Six-year clinical and histologic study of sinus-lift grafts.-1996International journal of Oral and Maxillofacial implants II: 26-34.

2. Yildrim, M., Spiekermann, H., Handt, S., Edelhoff, D. - Maxillary sinus graft augmentation with the xenograft biooss and autogenous intraoral bone for qualitative improvement of the implant site: a histologic and histomorhometric clinical study in humans. International journal of Oral and Maxillofacial implants
- $2001-16: 23-33$

3. Zerbo, I.R., Bronckers, A.L., de Lange, G.L., van Beek, G.J., Burger, E.H. - Histology of human alveolar bone regeneration with a porous tricaltium phosphate. - 2001 - Clinical oral Implants Research - 12: 379 - 384

4. Smiler, D. C., Johnson, P. W., Lozada, J. L., Misch, C., etc.- Sinus lift grafts and endosseous implants. Treatment of the atrophic posterior maxilla. - 1992 Biochemical /society Transactions 28: 362 -368 .
5. Hoexter, D.L. - Bone regeneration graft materials - Journal of oral implantology - 2002 - 28: 290 - 294

6. Boyne, P.J., James, R.A. - Grafting of a maxillary sinus floor with autogenous marrow and bone - Journal of oral surgery - 1980 - 38: 613 - 616

7. Browaeys H., Bouvry P., De Bruyn H. - A literature review on biomaterials in sinus augmentation procedures. Clinical implant dentistry and related research $2007-9: 166-177$

Address for correspondence:

Tihomir Georgiev

Str. Hristo Popovich Nr.18

Varna 9000 Bulgaria

e-mail: tgeorgievphd@yahoo.com 